\title{
Silêncio e segredo: sobre o desenvolvimento da capacidade de pensar
}

\section{Silence and secrecy: on the development of the ability to think}

\author{
El silencio y el secreto: el desarrollo de la capacidad de pensar
}

\section{Sergio Gomes*}

Universidade Federal do Rio de Janeiro - UFRJ, Rio de Janeiro, Rio de Janeiro, Brasil

\begin{abstract}
RESUMO
Os psicanalistas sempre se depararam com o não verbalizável, o não dito, o não comunicável, ao tratar dos diversos males da alma daqueles que chegavam ao seu consultório. Quando o silêncio se faz presente em uma sessão de análise, ele manifesta uma pluralidade de sentidos com os quais todo o analista deve manejar no tratamento clínico. Assim, o presente trabalho objetiva analisar as interfaces entre silêncio e segredo na psicanálise, considerando-os como um desenvolvimento da capacidade do pensamento. Investiga-se os conceitos de rêverie, segredo e a capacidade de pensar a partir das teorias dos analistas da Escola Inglesa de Psicanálise. O autor defende a comunicação silenciosa, por um lado, e o direito ao segredo, por outro, como uma condição necessária a ser sustentada pelo analista na constituição psíquica do "eu", a partir de uma análise não invasiva, para que o paciente desenvolva a capacidade de pensar, sonhar e, posteriormente, se comunicar.
\end{abstract}

Palavras-chaves: silêncio, segredo, pensar, Winnicott.

\begin{abstract}
Psychoanalysts always faced with the not verbalized, the unspoken, the not communicable, when dealing with various ailments of the soul of those who came for treatment. When silence is presented in an analysis session, it manifests a plurality of directions with which every analyst must manage the clinical treatment. Thus, the present paper aims analyze the interfaces between silence and secrecy in psychoanalysis, considering them as a development of the capacity of thought. The author investigates the concepts of reverie, secret and the ability to think from the theoretical contributions of the analysts of the English School of Psychoanalysis. The author defends the silent communication and the right to secrecy as a necessary condition to be sustained by the analyst in the psychic constitution of the "self", from a non-invasive analysis, so the patient will develops the ability to think, to dream and to communicate.
\end{abstract}

Keywords: silence, secrecy, think, Winnicott.

\section{RESUMEN}

Los psicoanalistas siempre enfrentan al no verbalizado, lo no dicho, a no transmisibles, cuando se trata de varias dolencias del alma de aquellos que vinieron para el tratamiento. Cuando el silencio se presenta en una sesión de 
análisis, se manifiesta una pluralidad de direcciones con la que cada analista debe administrar el tratamiento clínico. Así, este artículo tiene como objetivo analizar las interfaces entre el silencio y el secreto en el psicoanálisis, considerándolos como un desarrollo de la capacidad de pensamiento. El autor investiga los conceptos de reverie, secreto y la capacidad de pensar a partir de los aportes teóricos de los analistas de la Escuela Inglesa de Psicoanálisis. El autor defiende la comunicación silenciosa y el derecho al secreto como una condición necesaria para ser sostenida por el analista en la constitución psíquica del "yo", a partir de una análisis no invasiva, de modo que el paciente desarrolla la capacidad de pensar, soñar y posteriormente comunicarse.

Palabras-clave: silencio, secreto, pensar, Winnicott.

\section{Introdução}

A linguagem sem dúvida serve também para a comunicação entre os homens; mas, aí, sua necessidade vem simplesmente do fato de que os homens, seres pensantes que são, têm a necessidade de comunicar seus pensamentos; os pensamentos, para acontecer, não precisam ser comunicados; mas não podem acontecer sem ser falados - silenciosa ou sonoramente, em um diálogo, conforme o caso.

Hannah Arendt

A vida do espírito, 1995

Com um tratamento centrado na palavra, os psicanalistas sempre se depararam com o não verbalizável, o não dito, o não comunicável, ao tratar dos males da alma daqueles que chegavam ao seu consultório: o silêncio. Silêncio do paciente ou silêncio do analista, silêncio crônico ou silêncio efêmero, silêncio de resistência ou silêncio de abertura do inconsciente, silêncio de vida ou silêncio de morte, não importa: o silêncio se faz presente em uma sessão de análise, manifestando uma pluralidade de sentidos com que os analistas até hoje se defrontam, colocando-lhes problemas os quais eles devem tentar solucionar.

A comunicação que se instala entre o par analítico liga os inconscientes e os corpos que ali dividem aquele espaço, trabalhando silenciosamente e retendo as palavras que não são pronunciadas, os sofrimentos que estão por vir, a dinâmica da transferência que se estabelece pouco a pouco, o sentido da confiabilidade e empatia que avançam como resultante desse encontro, e os sentimentos oriundos do analista a partir do que é vivido em conjunto com o seu paciente pela transferência e contratransferência. Às vezes, o tormento do não dito sacode o corpo e não chega à consciência do analisando (poderia, de igual modo, sacudir o corpo do analista, na medida em que ele intervém com sua palavra), fazendo com que o silêncio seja a 
mais perfeita tradução de uma alma em busca de sentido. Alma do analisando e corpo do analista; alma do analista e o corpo do analisando são todas figuras que vão se constituindo e se delimitando cada vez em que o processo terapêutico vai avançando.

A psicanalista Françoise Coblence (2010) problematiza a noção de alma e corpo na psicanálise a partir de um aforisma de Freud, relativo à origem da espacialidade do aparelho psíquico, quando este afirma: "A psique é estendida, e dela não se diz nada" (Freud, 1996a, p. 318). Para a autora, a alma se estende por todo o corpo, está em toda parte, silenciosamente, insinuada, deslizada, infiltrada, impregnada, modelada e onipresente. O que a autora chama de alma é o brilho que sacode o corpo para fora de si mesmo quando ele é comparado a outro corpo, o brilho que está preso no espasmo, no soluço ou no suspiro de cada um. A alma é, portanto, a psique unida ao corpo que, ao encontrar outra alma, ou, melhor dizendo, um outro corpo, tem libertado a palavra e a escuta, posto que é sempre nesse encontro que ambos os corpos, do analisando e do analista, são afetados. A afetação é da ordem da escuta, do toque que é dado pelos "dedos das palavras", da "pele da linguagem" ou do "tremor do desejo" na comunicação silenciosa estabelecida por meio do campo transferencial, contratransferencial ou das identificações projetivas vividas no setting (Coblence, 2010).

Esta comunicação silenciosa pode tomar forma de um segredo torturante pelo aparelho psíquico, conforme Freud e Breuer (1996b) já anteviam nos primórdios da psicanálise. Segundo os autores, o próprio falar é um reflexo ou uma enunciação de um segredo, uma confissão a um outro que lhe escuta e solicita intervenção. Silêncio e verbalização, silêncio e segredo, são funções que precisam ser investigadas pela clínica psicanalítica contemporânea.

A partir dessas considerações, o presente trabalho objetiva investigar o lugar do silêncio e do segredo na psicanálise em sua vertente não clássica, considerando-os como um espaço reservado ao "eu" para que o paciente desenvolva a capacidade de pensar, sonhar e posteriormente se comunicar.

\section{Silêncio e rêverie}

De acordo com Masud Khan (1989), psicanalista da Sociedade Britânica de Psicanálise, membro do Grupo Independente (Independent Group) e herdeiro teórico de Donald Winnicott, o silêncio em uma sessão analítica pode ser compreendido a partir de dois lugares, nitidamente distintos: um lugar no qual o segredo habita e um lugar onde se dá a comunicação entre o paciente e seu analista. No tocante ao primeiro, o segredo vivido pelo paciente é o lugar reservado para que as histórias, lembranças, sonhos, 
recordações e elaborações psíquicas possam ser vividos tanto internamente como externamente como um espaço potencial, ou seja, um lugar no qual o paciente vivencia no seu processo analítico (Khan, 1989). Desse modo, "o dentro e o fora", "o interno e o externo", "o objetivo e o subjetivo" constituem-se como espaços mutuamente inter-relacionados. Esses espaços não são exclusivos do paciente, mas partilhados pelo analista e pelo analisando numa experiência mútua. A situação analítica, de modo geral, atende às demandas dos pacientes de acordo com o processo analítico, com a relação analítica - baseada fundamentalmente na transferência, e no enquadre. Clinicamente, quando somos capazes de possibilitar o sentimento de confiabilidade com estes pacientes, eles podem compartilhar seus segredos conosco (Khan, 1974). Mas, ainda de acordo com psicanalista indiano, o processo analítico atualiza, pela interpretação, o significado oculto discutido por Freud; a significação ausente, defendida por André Green e a significação potencial das comunicações do paciente, defendida pelo próprio Khan (1974, 1989).

Para que isso ocorra, duas funções precisam ser adicionadas ao papel desempenhado pelo analista na relação transferencial: o de "holding", conforme exposto por Winnicott (2005; 1983c; 1983b; 1994f) e o de "continente $\leftrightarrow$ contido", conforme defendido por Bion (1994). O conceito de holding (sustentação), em Winnicott, implica que o analista pode funcionar como um pano de fundo no qual o paciente pode se sentir cuidado, não só pelo corpo do analista que se faz presente, mas pelo próprio ambiente analítico. O terapeuta, à semelhança do ambiente materno para o bebê, sustenta o paciente por meio do enquadre clínico, de sua escuta profunda, de intervenções e interpretações, assim como de sua presença viva, muitas vezes se predispondo a ser o primeiro ambiente em que 0 sujeito pode vivenciar experiências primitivas de self. $O$ conceito de holding winnicottiano pode ser complementado pelo conceito de "continente $\leftrightarrow$ contido" de Bion.

Para Ogden (2010), o sentido do conceito de "continente $\leftrightarrow$ contido" diz respeito não só àquilo que pensamos, mas à forma como pensamos, como processamos a experiência vivida e ao que ocorre psiquicamente quando somos incapazes de fazer um trabalho psicológico com aquela experiência durante uma análise (Ogden, 2010 , p. 127-128). Um continente é aquele no qual a mãe absorve e tolera os estados emocionais de seu bebê, os transforma e os "interpreta", do mesmo modo como o analista o faz no trabalho clínico. Assim, o continente não é uma "coisa", mas um processo, uma capacidade que permite o trabalho psicológico operando com a capacidade de pensamento para o indivíduo, se constituindo em um "sonhar inconsciente", um "devaneio pré-consciente" e uma "reflexão consciente". Essa forma de manejo da técnica analítica se constitui 
como uma intersubjetividade irredutível vivida pela dupla. O paciente, nesse sentido, é capacitado a conversar por meio da mãe/analista com seu próprio outro self ( $\mathrm{m} / \mathrm{other})$, inconsciente e infinito (Grotstein, 2010).

A "mãe/outro" ( $m$ /other), com barra e não com hífen - "m" significando mãe e "other" significando outro, em nossa acepção, também é aquela que constitui no bebê o sentimento de alteridade (otherness) em oposição a uma "eudade" (Iness) (Ogden, 1996). Além disto, ela também lhe proporciona uma identidade, uma personalidade, uma corporeidade e um psiquismo (aí inclusos o ego e o self do bebê), possibilitados pela oferta do primeiro ambiente ou da primeira experiência de mundo que o bebê vai encontrar através da apresentação do seio, assim como pelos outros cuidados fornecidos por ela ao longo do desenvolvimento do infante. Ou seja, a "mãe/outro" (m/other) é aquela responsável pela matriz do psiquismo ou matriz da mente no mundo do bebê em desenvolvimento.

O analista, assim, pode assumir a forma de um continente no qual o paciente pode depositar todos os conteúdos vividos no campo afetivo e emocional, ao mesmo tempo em que é depositário de todo o amor e todo o ódio advindos do paciente. A esta capacidade de se constituir ao mesmo tempo como um continente e um conteúdo para o paciente, Bion (1984) denominou de "função de rêverie", ao passo que Winnicott denominou de "mãe-objeto".

Segundo Bion, o amor da mãe é expresso por meio da rêverie materna, que transforma os ingredientes incontroláveis da experiência bruta em material que pode ser pensado, repensado e se constituir como objeto de reflexão. A rêverie materna, diz o autor, é um estado de espírito receptivo a qualquer objeto mental oriundo da criança. Por outro lado, a rêverie, em seu sentido clínico, é o modo de se abrir a todos os níveis da consciência do analista, tanto no nível físico quanto mental e emocional, de tal modo que ele se torna disponível e receptivo às experiências dos pacientes ou de si mesmo. A rêverie é, a um só tempo, um estado que a mãe ou o analista devem alcançar, e uma atividade que deve ser exercida junto ao bebê ou ao paciente.

Para o psicanalista James S. Grotstein, Bion ainda adicionou quatro funções à função "continente $\leftrightarrow$ contido", quais sejam: a "rêverie materna" - constituída por uma capacidade de sustentar toda ação dirigida pelo bebê à mãe em termos emocionais e afetivos; a função alfa - que se refere a uma capacidade de lidar de modo criativo e pessoal com os dados da experiência emocional oriunda do bebê; o sonhar - compreendido como um espaço onde podem ser projetados os conteúdos imaginários do infante; e o fantasiar - lugar privilegiado da criatividade (Grotstein, 2010). As três últimas constituem o conjunto de transformações facilitado pelo estado de "rêverie 
materna". Em termos clínicos, a "rêverie do analista" é o espaço no qual se dá a sustentação das emoções e dos afetos do paciente; a forma com que ele lida com suas experiências emocionais; 0 "ensonhamento" durante a sessão e o desenvolvimento do espaço potencial, lugar da criatividade. Tal como afirma Ogden, a "rêverie do analista" permite ainda a emergência de pensamentos, sentimentos e imagens em relação ao paciente advindos do seu interior:

A conversação inconsciente que durante 0 sono nós experimentamos como um ato de sonhar, no setting analítico nós experimentamos como sendo uma rêverie. As rêveries do analista são sonhos acordados. A rêverie pode ter praticamente qualquer forma, mas geralmente, em minha experiência, apresenta-se obliquamente à consciência na mais discreta e cotidiana das formas: como "ruminações", devaneios, fantasias sexuais, trechos de filmes, frases musicais ou trechos de poesia "audíveis", sensações corporais, e assim por diante (Ogden, 2001, p. 5).

Assim, Bion inclui o silêncio no processo analítico a partir de sua representação na figura do analista. Este deve renunciar à memória, ao desejo e à compreensão de tudo o que ocorre na sessão. Para ele, há uma necessidade de que o analista abstenha-se de qualquer representação mental obtida por um disciplinamento permanente e ativo durante o processo analítico, de modo a apontar o silêncio com uma figura do vazio. Mas o silêncio não é interpretado à luz do ponto de vista fenomênico. Pelo contrário, para Bion, o silêncio constitui a "identidade do analista", na qual ele experimenta um estado de vacuidade interna - estados de silêncio - que funciona como um "continente" do funcionamento mental do paciente. O silêncio, como figura do vazio, é condição indispensável para a capacidade intuitiva do analista - em substituição e em oposição ao "suposto saber analítico". Trata-se de um instrumento que, no pensamento do autor, permite atribuir uma significação aos elementos primitivos que surgem no campo mental do paciente e capturados pelo registro dos sentidos inconscientes do analista no setting.

O setting analítico, por sua vez, viabiliza uma conversa assimétrica entre o paciente e o analista. Mas essa conversa se dá na fronteira do sonho (conversations at the frontier of dreaming) (Ogden, 2001), e é ao mesmo tempo uma conversa consciente e inconsciente, ou seja, um encontro entre dois inconscientes que se passa no interior da experiência psíquica de cada um dos participantes dessa comunicação. A fronteira, assim definida por Ogden (2001), é o lugar no qual ocorrem o sonhar e a rêverie, onde podem ser vividos 0 brincar, o jogar e a criatividade do paciente. O analista não brinca apenas com os pacientes de menor idade, mas também com 
pacientes adultos, por meio das palavras, expressões, histórias, ora se utilizando criativamente de literatura, poesia, trechos de filmes ou livros, ora da sua própria criatividade exteriorizada.

O paciente, por sua vez, tem duas maneiras distintas de usar o espaço analítico: como espaço concreto de uma área onde ele e o analista estão, e como um espaço potencial onde eles podem manter os estados de alma das experiências psíquicas que suas capacidades do eu não podem mais atualizar. É daí que Winnicott emprega o termo "espaço potencial", tal como ele o compreende no "jogo dos rabiscos" e no brincar (Winnicott, 1994a; 1994c; 1994e). Este "espaço potencial" vivido no papel através do "jogo dos rabiscos" é um espaço compartilhado onde o analista e a criança, juntos, podem avançar e compartilhar a cada momento significativo do processo analítico. Este espaço potencial também é vivido cada vez que o analista empresta parte do seu self e do seu ego para o paciente depositar o que foi vivido em termos de mundo interno.

Todos esses espaços podem aparecer em brincadeiras e jogos, associações livres, sonhos, antes mesmo de serem compartilhados pela dupla analítica. O segredo que faz parte do mundo interno do paciente só será revelado ou compartilhado com o analista quando houver a aceitação tácita da experiência de mutualidade, quando estiver instalado o sentido de confiabilidade vivida pela dupla e quando a empatia e, consequentemente, a transferência se instalarem na cena analítica, permitindo ao analisando compartilhar o que foi vivido como um segredo.

Assim, o "segredo do paciente" pode ser definido como um "espaço potencial secreto" que deve ser elaborado por ele durante o curso de sua análise, para só assim vir a emergir por meio da comunicação verbal (Khan, 1989). Podemos esperar que a pessoa conte ou não fatos da sua vida antes que ela possa achar aquela mutualidade da confiança e privacidade que é a essência do método psicanalítico.

\section{Um outro lugar para o segredo na análise}

De acordo com Masud Khan (1974), a criação de um segredo também parece engendrar um "espaço vazio" na psique do indivíduo que o oculta de maneira racional por meio de eventos de todo tipo, intrapsíquicos e interpessoais. Cabe a nós, clínicos, estabelecer uma distinção entre a experiência autêntica desses indivíduos e seus comportamentos racionais. Eles devem permitir o compartilhamento de suas experiências e não simplesmente traduzi-las em fantasmas ou em gestos sintomáticos. A "pseudologia fantástica", ou seja, a mentira patológica, pode muitas vezes dar ao indivíduo um espaço potencial similar (Khan, 1974, p. 54-55). Esse espaço potencial pressupõe um lugar onde o paciente possa brincar e jogar com seus 
fantasmas e experiências do seu mundo interno, antes mesmo que ele possa atender às regras da associação livre. Se o paciente encontra acolhimento no uso desse espaço potencial, ele pode vir a falar de si mesmo e a análise termina por conceder o espaço onde o paciente pode viver o seu self verdadeiro (Khan, 1976).

Ora, essa afirmação também é compartilhada por Christopher Bollas (1976), membro da Sociedade Britânica de Psicanálise e igualmente pertencente ao Grupo Independente (Independent Group), ao se referir à linguagem do segredo entre a mãe e o bebê. Para ele, a mãe descobre o discurso secreto do infante para iniciá-lo em uma nova ordem simbólica (momento da desilusão). A cultura mãe-bebê é, em essência, um efeito pré-histórico, sentimento de um tempo ou de um lugar ausentes no mundo.

A iniciação do bebê na sua história pessoal, familiar e social é facilitada quando a mãe, em um certo sentido, trai o segredo entre eles, iniciando-o em uma nova ordem simbólica, não aquela da fusão materno-infantil, mas no processo de desilusão/frustração, no qual o bebê passa a estabelecer relações com objetos da realidade compartilhada. A partir desse estado, a mãe e a criança dividem as lembranças de seu segredo cujo conteúdo desaparece com o tempo, encontrando um novo lugar no inconsciente do indivíduo, inscrito no idioma enigmático de um caráter pessoal e só acessível por meio da análise.

O processo de análise, para Bollas, oferece aos pacientes um espaço onde eles podem compartilhar a cultura do segredo vivido na relação mãe-bebê com a pessoa do analista. De que modo? Por exemplo, quando afirmamos para o paciente que o espaço analítico é um espaço confidencial, nós queremos dizer que a relação (transferencial) estabelecida entre o par analítico é um segredo compartilhado apenas por aquele par, seja o paciente adulto ou criança. No interior do espaço analítico, a transferência e a contratransferência advêm de um discurso que permite partilhar agora aquele segredo vivido entre a mãe e o bebê na relação do analisando com o analista.

\section{0 paradoxo da comunicabilidade humana em Winnicott}

Quando Winnicott (1983a) publica "Comunicação e não comunicação levando ao estudo de certos opostos", ele estava interessado em entender o paradoxo na comunicabilidade humana, o lugar do silêncio nessa comunicação, bem como o que faz com que o indivíduo tenha o direito de não se comunicar durante as sessões de análise, independente do período em que esse silêncio se faça presente.

Sabemos que, durante um processo analítico, os pacientes atravessam fases que vão da "lua de mel" à "lua de fel" no início da 
análise, ou seja, da verborragia e do tudo dizer, à introspecção, ao retraimento e às dificuldades de expor em palavras o seu sofrimento psíquico.

Por meio de uma "economia das palavras", o indivíduo se recolhe em seu mundo interno, fechando-se, protegendo-se e tornando-se incapaz de fornecer ao seu analista informações importantes para o bom desenvolvimento de seu processo clínico. Até que a transferência esteja instalada na relação analítica, e que a empatia e a confiabilidade sejam coadjuvantes deste processo, haverá sempre a possibilidade de sucumbir ao "recordar, repetir e repetir", até que se possa chegar ao "recordar, repetir e elaborar", sobretudo com pacientes neuróticos. Até lá, a comunicação de determinados aspectos essenciais da vida do paciente estará ausente da cena analítica, ora sustentada por um momento de hesitação, ora por um momento de resistência, ou ainda porque o que precisa ser posto em palavras pelo paciente permanece como um segredo inconfessável para ele mesmo. Ou seja, o paciente ainda não está preparado para ouvir de si mesmo o que tem para compartilhar com seu analista.

Quando o paciente assume uma atitude de reserva, antes de passar, o analista, a interpretar esse fenômeno como um movimento de resistência, ele pode estar tentando conquistar um direito: o direito de pensar, fantasiar, sonhar e elaborar, por meio do silêncio, seus conteúdos internos. Este silêncio, entre tantos significados, pode levar o paciente a esconder da cena analítica conteúdos indizíveis para serem vividos no palco de sua análise.

É importante para o paciente saber que ele é livre para estar em silêncio, quanto é importante que saiba que é livre para falar. Privilegiar a fala sobre o silêncio, a revelação sobre a privacidade, a comunicação sobre a não comunicação, parece ser tão não analítico quanto privilegiar a transferência positiva sobre a negativa, a gratidão sobre a inveja, o amor sobre o ódio (Ogden, 1999, p. 123).

Quando a confiabilidade e a transferência estão estabelecidas na situação clínica, é comum que alguns pacientes procurem criar um sentido de privacidade por meio de faltas, atrasos, momentos de mutismo, e experimentarem a vivência de uma vida privada. De acordo com Ogden (1999), se o silêncio for usado como forma defensiva, é importante reconhecer a necessidade que o paciente tem de vivenciar a sua privacidade no processo de análise e seu modo de realizar uma comunicação transferencial por meio do silêncio. Se na situação analítica nós interpretarmos esses fenômenos como resistência ou puramente atuação (acting out) do paciente, estamos repetindo, na sua história, a falha ambiental que provavelmente veio a sofrer no curso do seu desenvolvimento, demonstrada pela 
onipresença avassaladora do analista que proíbe o direito de alcançar um espaço privado.

Para Winnicott, é importante que o espaço analítico sustente uma tensão dialética entre o comunicar e o não comunicar, e isso pode ser conquistado por meio de mudanças sutis na regra fundamental da psicanálise, conforme definida por Ogden: "Eu vejo nossos encontros como uma oportunidade para você dizer tudo o que você quer dizer, quando quiser dizer, e para que eu responda da minha maneira. Ao mesmo tempo, deve haver um espaço para a privacidade, para nós dois" (Ogden, 1999, p. 128). Trabalhar com o self do paciente, sua organização e sua constituição, não é só uma questão de palavras verbalizadas, mas de um "gesto" por parte do analista que acolha a aquisição da capacidade de pensamento do paciente, de forma privada, e permeada por momentos de silêncio.

A conquista da capacidade de pensar e, consequentemente, a impossibilidade de revelar determinados aspectos da sua vida constituídos como um segredo já haviam sido esboçadas em outros trabalhos de Winnicott $(1975 ; 1978 ; 1994$ e), no contexto dos objetos e fenômenos transicionais. Quando Winnicott analisou esses fenômenos, ele estava interessado na primeira posse não eu do bebê durante o período que marca a transicionalidade e o uso do objeto. Trata-se da área intermediária que se constitui na experiência subjetiva do bebê "entre o polegar e o ursinho, entre o erotismo oral e a verdadeira relação com objeto, entre a atividade criativa primária e a projeção do que já foi introjetado, entre o desconhecimento primário de dívida e o reconhecimento desta" (Winnicott, 1978, p. 390). Os objetos transicionais proporcionam ao bebê uma relação com a mãe como um objeto bom e podem ser projetados em objetos não eu. É importante para o bebê o reconhecimento deste objeto localizando-o fora, dentro, na fronteira, entre o mundo interno e o mundo externo, bem como a capacidade do bebê de criar, imaginar, inventar, originar e produzir um objeto com o qual ele possa se relacionar afetuosamente e se comunicar.

Por outro lado, os fenômenos transicionais dizem respeito à dimensão do viver criativamente, e não dependem nem da realidade interna, nem da realidade externa, mas de um espaço em que ambas as realidades podem habitar, separando o que é vivido no interior e no exterior do bebê, ou seja, o espaço potencial, local onde o self pode repousar e onde se localiza a experiência cultural (Abram, 2000). Com isso, podemos ver claramente que a forma com que o bebê se relaciona com o objeto externo se constitui como a matriz para o simbolismo e para a criatividade do bebê. O objeto transicional não tem por objetivo encarnar um objeto real, pelo contrário, ele pode se constituir como um fenômeno no qual se dá a comunicação do bebê. 
Por definição, o balbucio de um bebê e o modo como uma criança mais velha entoa um repertório de canções e melodias, enquanto se prepara para dormir, incidem na área intermediária enquanto fenômenos transicionais, juntamente com o uso que é dado a objetos que não fazem parte do corpo do bebê, embora ainda não sejam plenamente reconhecidos como pertencentes à realidade externa (Winnicott, 1978, p. 390).

Assim, quando o bebê vai dormir, ele pode empregar uma palavra, uma melodia ou até mesmo um maneirismo corporal que adquire uma importância vital durante esse momento, que se constitui como uma defesa organizada contra a ansiedade do tipo depressiva. Quando o processo maturacional do bebê encontra-se um pouco mais adiantado, ele pode empregar movimentos acompanhados de sons, balbucios, ruídos produzidos pelo seu corpo ou até mesmo as primeiras notas musicais. Esses fenômenos demarcam uma atividade no mundo interno do bebê possibilitados pela ação do pensamento, que, segundo Winnicott, demarca a constituição do seu psiquismo. Assim, afirma o autor, podemos supor que pensar, imaginar, devanear ou fantasiar se vinculem às experiências funcionais do bebê as quais se denominam fenômenos transicionais (Winnicott, 1978).

Esses fenômenos, muitas vezes, podem se dar em absoluto silêncio, na quietude vivida pelo bebê a partir da internalização de um objeto bom. Muitas vezes, podemos encontrar bebês que estão brincando sozinhos, olhando para um boneco, se relacionando com um pedaço de pano, sorrindo para um móbile, imaginando, fantasiando, criando imaginativamente o mundo, uma vez que pequenas doses deste mundo já lhe foram ofertadas pelo ambiente materno. Esse processo se dá primordialmente em silêncio e constitui-se na capacidade para poder pensar, tanto no bebê como no indivíduo adulto. $O$ desenvolvimento da capacidade de pensar igualmente pertencente às experiências que fazem parte do mundo interno do bebê, uma vez que a mãe constitui, por meio do holding, a sua matriz psicológica (Ogden, 2013).

Essa matriz psicológica, que, em sua essência, origina o psiquismo do bebê, se dá a partir do provimento de um ambiente do qual o bebê necessita. Uma vez que a mãe se coloque nesse lugar de continente, ele consegue internalizá-la como um objeto bom, guardá-la dentro do seu mundo interno, para daí experimentar momentos de solidão/solitude, desenvolvendo a capacidade para estar só. Ao mesmo tempo, no período que marca a transicionalidade, ele poderá fazer uso de objetos não eu e, durante o uso de certos fenômenos (transicionais), tranquilizar-se e acalmar-se quando se recolher em sua solidão essencial. De acordo com Ogden (2013), o período no 
qual os fenômenos transicionais emergem pode ser compreendido como uma fase da internalização pelo bebê da matriz psicológica.

Assim, a matriz psicológica do bebê se constitui a partir de uma série de momentos experimentados por ele na relação com a mãe: vivências de acolhimento pela mãe ambiente, internalização da mãe como objeto bom, criação do mundo interno, experiências de ilusão, desilusão, frustração, elaboração e fantasias dentro do espaço potencial, recolhimento em sua solidão essencial e o desenvolvimento da capacidade de estar só. Nesse continente, 0 bebê pode se experimentar como um ser isolado, criar imaginativamente o mundo e entrar no campo simbólico. Esta foi a matriz originária a partir da qual Winnicott concebeu a comunicabilidade humana, ou seja, uma matriz de um inconsciente não verbal.

Do ponto de vista do analista, entrar em contato com esse mundo etéreo e evanescente da matriz do inconsciente não-verbal, só é possível por meio da linguagem e da comunicação desses processos vividos no interior do sujeito. Do ponto de vista do paciente, pode ser que esses momentos vividos no seu processo analítico sejam a primeira oportunidade de experimentar sua criatividade, sua capacidade imaginativa e a elaboração de eventos conscientes e inconscientes, vividos com a mãe/outro $(\mathrm{m} / \mathrm{mother})$ por meio do silêncio e do segredo. Ou seja, esta é uma oportunidade para o paciente pensar secretamente, em oposição ao imperativo do dizer tudo.

\section{Direito ao segredo: sobre a capacidade de pensar}

Aulagnier (1990), malgrado não pertença à vertente da Escola Inglesa de Psicanálise, contribuiu para este debate com um texto lapidar intitulado "Direito ao segredo: condição para poder pensar". De acordo com a autora, preservar-se o direito e a possibilidade de criar pensamentos exige do indivíduo que ele possa escolher quais pensamentos gostaria de comunicar e a quem comunicá-los. Trata-se de uma condição vital para o funcionamento do "eu" (ego). Esse direito está claro no enquadre analítico. Todo analista sabe que, em determinados momentos da análise, o paciente não estará preparado para the revelar assuntos de sua vida até que se estabeleça um sentimento de confiança mútuo, muito embora, alguns analistas na sua vertente clássica também reconheçam, mais uma vez, uma ligação entre o pensar secretamente e o mecanismo do recalque.

Se não se concedesse o direito de pensar representações fantasísticas, o Eu se veria obrigado a dispender a maior parte de sua energia recalcando fora de seu espaço esses mesmos pensamentos $\mathrm{e}$, fato mais grave, interditando o acesso ao 
conjunto de temas e termos que se aproximam dele tendo como consequência o perigoso empobrecimento de seu próprio capital ideacional: conhece-se o silêncio que, por um processo de contaminação, pode-se instalar numa sessão se o sujeito decidiu, ainda que não sabendo abertamente, não pensar em tal ideia ou acontecimento do qual não quer nos falar. (...) A experiência pressupõe o respeito a um pacto pelo qual ele se comprometeu a fazer o possível para colocar em palavras a totalidade de seus pensamentos: mas, ainda é preciso saber respeitar a distância que separa a renovação desse pacto de uma atitude que priva o sujeito de todo direito a um pensamento autônomo (Aulagnier, 1990, p. 259).

Aulagnier quer chamar a atenção para o fato de que pensar, imaginar, devanear, cantarolar, conversar imaginativamente com alguém, etc., são todos fenômenos constituintes da capacidade de pensamento do indivíduo. Se essa asserção é verdadeira, então podemos compreender que, no registro do "eu" (ego), a capacidade de fantasiar pressupõe a possibilidade de guardar determinados pensamentos em segredo e a perda do direito ao segredo comportaria, de um lado, o recalque, e, do outro, a impossibilidade do pensamento, tornando impossível a constituição do "eu".

Para a autora, toda a neurose comporta, em si mesma, o direito de o indivíduo manter pensamentos secretos que ele não tem condições de discutir, enquanto não passar pela elaboração. Era o que acontecia com as pacientes histéricas de Charcot, Breuer e Freud. A relação analítica não é constituída apenas pelo fato de o paciente exprimir pensamentos, afetos e desejos e não receber do analista nenhuma resposta em retorno, como se houvesse uma neutralidade tácita, conforme defendeu Freud em alguns dos seus textos técnicos. Aquilo que é dito e aquilo que não é dito em uma sessão, por meio de palavras, afetam a dupla. O analisando pede uma resposta ao seu analista, que também não necessariamente pode responder por meio de palavras. Muitas vezes, esperamos meses para poder comunicar ao paciente uma interpretação sobre um determinado evento de sua vida, por entender que ele também não está preparado para ouvir aquela interpretação. Se o analisando pode ter o direito ao segredo e à capacidade de pensar, esta não é uma condição especificamente sua. $\mathrm{O}$ analista também pensa, fantasia, elabora sobre o que ouve do seu paciente, e pode igualmente guardar segredo não só sobre aquilo que é dito, mas, sobretudo, sobre aquilo que ainda não pode ser comunicado ao paciente sobre ele mesmo, tornando-o o depositário todo poderoso de um "segredo do seu segredo" (Aulagnier, 1990). A capacidade de pensar e de guardar segredo, portanto, é dupla: do analista e do analisando. "Tudo o que foi descrito e analisado sob os termos de dependência, regressão e frustração, não-reciprocidade na 
situação analítica, encontra sua primeira causa nisso que se apresenta injustamente como uma simples condição técnica, esquecendo aquilo que a "lei" da associação dita livre comportaria de ilegal, de inassumível, de escandaloso em qualquer outra situação" (Aulagnier, 1990, p. 261).

A condição para poder pensar, assim descrita pela autora, encontra reforço, principalmente, nos tipos clínicos da neurose, mas também pode aparecer de igual modo em distúrbios psicóticos:

Enquanto o analista interrogar a função do pensar secretamente no registro único da neurose, poderá não perceber senão seu resultado mais aparente, embora essencial: permitir ao sujeito fantasiar sem ter que desaparecer no sono ou pagá-lo por um compromisso sintomático. Escapar-lhe-á outra condição que torna essa função possível: é preciso que pensar secretamente tenha sido uma atividade autorizada e fonte de prazer para que sobre essa experiência se enxerte a fantasia diurna e não o inverso (Aulagnier, 1990, p. 263).

E como a capacidade de fantasiar do indivíduo se torna possível no seu psiquismo, senão a partir da provisão de um ambiente que possibilite que essa função seja exercida? Nesse sentido, Aulagnier dialoga frontalmente com a teoria das relações de objetos e com a teoria do desenvolvimento emocional de Winnicott ao afirmar que essa capacidade de pensar em segredo, de produzir fantasias, é, em essência, o desenvolvimento de uma capacidade que já se encontrava no bebê quando ele passou a fazer uso tanto de objetos como de fenômenos transicionais, retirando desta capacidade um prazer resoluto de um objeto bom internalizado, de um ambiente que Ihe possibilitou o desenvolvimento dessa capacidade, podendo representar no seu mundo interno o mundo que lhe foi apresentado em pequenas doses pela mãe/outro $(\mathrm{m} /$ other). Segundo o pediatra e psicanalista inglês, o pensar começa como uma maneira pessoal que o bebê desenvolve para lidar com os fracassos da adaptação materna às suas necessidades, tolerando tanto o fracasso da adaptação a necessidades do ego, quanto a frustração do instinto que produz o estado de tensão interna. Assim o bebê pode acreditar no ambiente materno e ambos tornam-se aptos a desfrutar do sentido da confiabilidade (Winnicott, 1994d). Dito de outro modo, fantasiar, pensar, criar imaginativamente é dar ao indivíduo a possibilidade de se comunicar empaticamente com o outro por meio do seu silêncio, guardando segredo dos eventos internos que passam pela ação do pensamento.

Por outro lado, é preciso considerar outra faceta do silêncio. Refirome ao silêncio da reflexão (musing) tal como formulado por Christopher Bollas (1992), ou o silêncio da elaboração e da 
perlaboração. Nesse silêncio, assim concebido, 0 analisando encontra-se como que "flanando", em um "estado sem forma". Não se trata de estados mentais ativos e sim de um "pensar intimamente", "estudar em silêncio", "meditar", "analisar", "construir interiormente". Este tipo de silêncio em nada tem a ver com estados regredidos ou pacientes em regressão. Ele pode se dar em qualquer momento da análise, no início, meio ou até mesmo antes do final de um processo analítico. Trata-se de um momento estético, uma memória do estado de ser, no qual o tempo, o espaço, o ritmo e o corpo do paciente não podem ser dimensionados. Na verdade temos aí um processo de construção interna que pode ser resultante de uma associação livre do paciente ou de algo que o analista Ihe disse.

Aqui, quatro condições são especialmente necessárias para o bom desenvolvimento de uma análise: primeiro, o analista deve compreender que o silêncio neste caso não remete propriamente a uma resistência e seu trabalho está em ajudar o paciente a desenvolver as capacidades de pensar, refletir e elaborar tal como pontuado por Aulagnier (1990), Bion (1984) ou Khan (1977a, 1977b, $1974,1989)$. Segundo, sua compreensão do uso do silêncio por parte do analisando oferece a ele a capacidade de usá-lo em sua própria análise - em sua forma positiva. Terceiro, uma vez que o analisando compreende isso, pode-se permitir o curso de uma regressão à dependência para, por fim, fazer uso da reflexão como uma habilidade receptiva no decurso de uma análise, sem que o analista se sinta constrangido ou mesmo ameaçado com os estados silenciosos do seu paciente (Bollas, 1992).

$O$ analista, nesse instante da análise, tem de ser capaz de renunciar às suas defesas contra a ansiedade, o medo da aniquilação, da perda de identidade, sua e de seu paciente. Concomitantemente, sua identidade deve permanecer distinta e seu sentido de realidade inalterado, mantendo a consciência no nível da realidade e da ilusão, ou seja, ele deve assumir uma posição de cuidado tal qual aquele observado na relação mãe-bebê ou mãe-suficientemente-boa, sem fazer da sua atitude profissional um traço dessa relação, mas, sim, estabelecendo uma relação direta e empática com o paciente. Feito isso, o analista pode-se almejar tolerar seu amor e seu ódio sem revidar, quando muito, sua indiferença e tolerar suas próprias emoções oriundas dessa relação, quando despertadas.

Este é o momento em que a intersubjetividade entra em cena no processo analítico, assemelhando-se àquele momento vivido na trajetória de vida do infante: um encontro entre inconscientes. Muitas vezes, o analista e o analisando experimentam isso como uma transmissão de pensamento: é a hora em que uma ideia, uma sensação ou até mesmo uma pergunta são capturados pelo inconsciente do outro e verbalizados por um deles, surpreendendo a ambos. Aqui também podemos observar o quanto de material 
transferencial e contratransferencial pode surgir no decurso de uma análise. Este é o mais perfeito exemplo de que haveria uma transmissão ou comunicação de inconscientes entre dois sujeitos em análise, e, como tal, esse processo intersubjetivo vivido no setting pode contribuir, facilitar ou promover a regressão à dependência, processo necessário para restituir as falhas ambientais anteriormente enfatizadas.

\section{Bion e a capacidade de pensar}

Um dos principais temas do trabalho do psicanalista Wilfred Bion se desenvolveu em torno da capacidade de pensar, cujo livro "Seconds Thoughts" reuniu suas principais ideias sobre o assunto. Para o autor (Bion, 1994), o pensar é uma atividade que depende do resultado satisfatório de dois desenvolvimentos mentais - dos pensamentos e do aparelho que proporciona a atividade do pensamento. Os pensamentos podem ser classificados conforme a natureza de sua história evolutiva, como pré-concepções, concepções ou pensamentos propriamente ditos, além de conceitos.

Para a psicanálise, tal como Bion a compreende, a capacidade para pensar no bebê se dá a partir da expectativa que ele tem em relação ao seio materno. Quando o bebê entra em contato com o seio, o produto final da ação do seu pensamento é uma "concepção" do seio, ou seja, uma expectativa inata de um seio que advém na mente do bebê. Trata-se de um "a priori" ou pensamento vazio. Mas se o bebê tem uma frustração relacionada à não apresentação do seio (ou dito de outro modo, de um "não seio"), o que ele pode experimentar é uma realização do seio em sua mente e uma frustração pela apresentação do "não seio". Assim, ele empreende um esforço para fugir da frustração, modificando-a. Se sua capacidade de tolerar a frustração for suficiente, o "não seio" se transforma em pensamento e o bebê desenvolve um aparelho para poder pensar. Portanto, a capacidade de tolerar a frustração oriunda da apresentação do "não seio" possibilita que a psique do bebê desenvolva o pensamento como um meio de superar a frustração vivida internamente. Por outro lado, a incapacidade de tolerar a frustração pode ser prejudicial para o desenvolvimento do bebê, obstruindo o desenvolvimento dos pensamentos e a sua capacidade de pensar.

A função-alfa, concebida por Bion, diz respeito a um instrumento de trabalho na análise dos distúrbios de pensamento, com o qual o analista sustentará, por meio da função de rêverie, a possibilidade que o paciente tem para conseguir pensar ou sonhar.

De acordo com Ogden (2010), Bion criou o termo "função-alfa" para se referir ao processamento dos "elementos-beta" proveniente das impressões sensoriais brutas, sob forma de pensamento e oriundas 
das experiências emocionais. Os "elementos-beta" são impressões sensoriais não processadas, e não podem ser ligados entre si nem utilizados em funções mentais tais como pensar, sonhar ou armazenar memória. Os "elementos-alfa", por outro lado, são elementos da experiência que podem ser ligados entre si no processo consciente e inconsciente de funções mentais. Por exemplo, se houver uma falha na função-alfa, isto significa que o paciente é incapaz de dormir e, consequentemente, sonhar, pois a função-alfa torna as impressões sensoriais em experiências emocionais disponíveis para a ação do pensamento. Se o paciente não é capaz de dormir, ele também não é capaz de sonhar, e se ele não se recolhe ao sono, ele é incapaz de despertar. Senão, vejamos:

Sonhar é um processo constante que ocorre tanto no sono quanto na vida de vigília inconsciente. Se uma pessoa é incapaz de transformar impressões sensórias brutas em elementos inconscientes da experiência que possam ser ligados, ela é incapaz de gerar pensamentos-sonho inconscientes e, consequentemente, não pode sonhar (seja durante o sono ou na vida de vigília inconsciente). A experiência de impressões sensórias brutas (elementos-beta) no sono não é diferente da experiência de elementos-beta na vida de vigília. Portanto, o indivíduo não pode dormir e não pode despertar, ou seja, ele não é capaz de diferenciar estar desperto e estar dormindo, percebendo e alucinando, a realidade externa e a realidade interna (Ogden, 2010, p. 19).

Assim, no curso de uma análise, tudo o que o analista pode fazer é possibilitar ao paciente "sonhar sonhos não sonhados e choros interrompidos" (Dream undreamed dreams and interrupted cries) na acepção de Ogden (2010). O analista precisa ter a capacidade e a responsabilidade de reinventar a psicanálise para cada paciente e continuar a reinventá-la durante o curso da análise e a cada nova sessão, pensando e sonhando, aprendendo e esquecendo (Thinking and dreaming, learning and forgetting) (Ogden, 2009).

Com efeito, de acordo com Andre Green (1977), a análise não se constitui meramente como um método de tornar consciente 0 inconsciente, de remover o recalque e libertar o afeto daquilo que produziu o sintoma, pelo contrário. A análise trata de uma intimidade a dois, por meio da qual o analista "cuida" (care) do seu paciente e o sustenta (holding) durante o seu processo. O sentido dado a "cuidar" (care), refere-se a bem mais do que isso. Trata-se de um cuidado especializado, dar atenção, importar-se, inquietar-se ou preocupar-se com o sujeito que tem diante de si. Isso é possível, quando o analista, na sua prática clínica, ajuda o paciente a se constituir como sujeito, servindo-se, às vezes, de ego auxiliar por meio da regressão 
em análise. O objetivo aqui não é apenas o de promover a cura do paciente.

Lembremos, pois, que todo paciente é fiel ao seu sintoma. De acordo com o próprio Winnicott, com certa frequência, temos que nos contentar em deixar o paciente ter de manipular a sintomatologia, sem tentar curá-lo do seu adoecimento (Winnicott, 1994f). Essa afirmação também é compartilhada por Masud Khan (1989) quando ele afirma que, no trabalho clínico, algumas vezes é mais importante sustentar (holding) uma pessoa viva do que livrá-la da sua doença. $\mathrm{Na}$ maioria das vezes, uma análise pode proporcionar ao indivíduo o desenvolvimento da capacidade de cuidar de si mesmo.

Em vez de rejeitar os pacientes cuja estrutura psíquica não consegue se adaptar ao enquadramento, cabe ao enquadramento modificar-se em função da estrutura do paciente. Os objetivos do tratamento serão também modificados. Não se trata tanto de "curar" o paciente, mas de torná-lo apto a tratar de si mesmo, a encarregar-se de si mesmo. O que equivale a dizer que o tratamento fornecerá ao paciente 0 enquadramento que lhe falta para conter seus conflitos. Isso não quer dizer reprimi-los, mas permitir-lhes o desaparecimento dos sintomas que o despertar e a conservação da vitalidade psíquica (Green, 1977, p. 8).

Se o enquadre pode mudar em função do sofrimento do paciente, logo, o seu silêncio pode ser compreendido em uma perspectiva diversa daquela da psicanálise clássica. De acordo com Green (1977), em alguns casos é preciso que o analista abandone a neutralidade típica com o objetivo de promover a verbalização do paciente, para que este aceite a plasticidade do objeto de transferência sem que 0 analista seja silencioso - o que não significa promover a "tagarelice" do analista em sua face mais ativa. O silêncio do analisando, no mais das vezes, permite que o analista tenha acesso à sua dor e ao seu sofrimento psíquico, dando a medida exata do seu desespero. Seu negativo não é a fala, mas o grito, e daí a importância da vitalidade do analista em certos momentos da análise. Assim, o analista pode proporcionar ao paciente a capacidade para poder pensar e elaborar as experiências vividas dentro do seu mundo interno.

\section{Considerações finais: pensando com Winnicott}

Conforme vimos, a Escola Inglesa de Psicanálise se notabilizou pelas suas inovações teórico-clínicas no que se refere ao estudo do silêncio em sua interface com o segredo. Muitos autores, oriundos do grupo independente, praticamente complementaram muitas das teorias uns 
dos outros. Foi o que aconteceu com Donald W. Winnicott, quando tratou de estudar e compreender a comunicabilidade humana.

Para Winnicott (1994b), a palavra "pensar", em inglês (to think), revela uma série de conotações diferentes para uma diversidade de ações almejadas. Isto foi demonstrado durante uma palestra no Centro de Educação Adicional de Devon, em janeiro de 1965, quando brincou com os diversos usos da palavra "pensar" em inglês:

Quando penso [think] no que me meti, fico aterrorizado. Primeiro me descubro rodeando [think round] o assunto, astutamente esperando safar-me pela exploração de uma distração. Mas então me descubro considerando [thinking around] a palavra "pensar". Começo então a inventar ou imaginar [think up] uma maneira de apresentar a comunicação que quero fazer. De vez em quando penso [think] em algumas palavras que é melhor deixar de dizer e faço uma nota mental: da próxima vez, pense [think] antes de aceitar este tipo de convite! Contudo, seria impensável [unthinkable] escapar de minha obrigação apresentando a desculpa de estar com gripe ou gota, de maneira que mergulho no assunto, apesar da advertência do poeta de que pensar [think] é ficar cheio de mágoa. Não há alternativa; tenho de refletir bem [think out] sobre esta coisa, sem esperanças de poder fazê-lo de modo completo [think it through]. Depois, terei de aceitar o que será pensado [thought of] de meus esforços, e não levá-lo a mal. Após, naturalmente pensarei [think of] em todas as coisas em que não pensei [though of]. Quão melhor teria sido ter pensado antes [thought forward] e predito as críticas de vocês (Winnicott, 1994b, p. 119).

Notem a diversidade de usos cotidianos do verbo "pensar" (to think, em inglês) mencionados pelo autor para expressar uma múltipla gama de funções: pensar, rodear, considerar, inventar, imaginar, impensável, refletir, pensar em, pensar antes ou rever, etc., e quais usos podemos fazer do mesmo verbo no desenvolvimento de uma criança: inventar, criar, imaginar, pensar, sonhar, devanear, catalogar, etc.

Winnicott está interessado em saber como o bebê expressa seu pensamento, como ele descobre a capacidade de pensar e como ele pode fazer uso deste dispositivo no processo maturacional, ao catalogar, categorizar e comparar, situação em que o funcionamento da mente está direcionado para uma tarefa específica e com certo objetivo limitado. Não nos esqueçamos que "Pensando sobre crianças" [Thinkg about Children] (Winnicott, 1997a) é um dos seus livros póstumos, que traz seus últimos artigos publicados. Há também o funcionamento corporal e sensório-motor da criança, além 
da forma como o bebê elabora o atendimento às suas necessidades físicas e emocionais a partir da elaboração imaginativa do funcionamento corporal, o que não se dá conscientemente. Assim, na sua concepção, a capacidade de pensar assume uma função mestre, qual seja, a de se constituir como um aspecto da imaginação criativa do bebê no período da dependência absoluta, servindo à sobrevivência da experiência de onipotência e promovendo a integração do indivíduo por meio da elaboração imaginativa dos elementos, sentimentos e funções somáticas (o psique-soma). De acordo com o autor, essa função é exercida em quase todos os bebês, que se especializam no que pensam e buscam palavras para poder se expressar; outros bebês se especializam em experiências diversas que não implicam em palavras: experiências auditivas, visuais, gustativas, olfativas ou outras experiências sensórias, ou ainda em lembranças e na imaginação criativa do tipo alucinatório (Winnicott, 1994b).

Quando o bebê tem uma reação endógena interna, a partir das necessidades físicas, corporais, fisiológicas, ele se comunica a partir de uma expressão motora (agitação de braços e pernas) e de seu grito (comunicação). Enquanto grita, o bebê pensa consigo mesmo que tem razão de fazê-lo porque os ruídos que escuta fora da cena indicam que alguém está vindo em seu socorro para atender suas necessidades (uma ação específica). Esta compreensão que o bebê tem do que está se passando dentro e fora dele mesmo, resulta na incapacidade crescente da mãe de fracassar na sua adaptação às necessidades do bebê. Assim temos dois tipos de bebês: aquele que rodeia a questão por meio do pensar e outro que o faz por meio da fantasia e pelo fruir imaginativo da sua experiência, antes mesmo que ela se torne real (Winnicott, 1994a).

O movimento para frente no desenvolvimento emocional de um indivíduo se dá pelo distanciamento de um estado desorganizado e no sentido da integração, do caos para a compreensão, da ignorância para o conhecimento e o poder de predizer, da dependência para a independência. O pensar é um dos aspectos do processo integrador, indo à frente da participação plena (Winnicott, 1994a, p. 122-123)

O mesmo pode ocorrer com pessoas adultas em meio a uma sessão analítica: algumas dessas experiências não podem ser alcançadas por meio da linguagem, e sim, por outras formas de entrar em contato com o outro, quer se trate de pacientes neuróticos, psicóticos ou personalidades narcísicas (casos limites ou borderline).

No desenvolvimento emocional do indivíduo, a tendência à integração é inata. As condições têm de ser más para que a 
integração não se torne um fato. A integração pode ser representada em termos das três dimensões do espaço, mas neste caso temos de acrescentar a quarta dimensão do tempo. Todos nós sabemos que quando um paciente começa a falar sobre o passado, ele está ao mesmo tempo começando a pensar no futuro (Winnicott, 1997a, p. 204).

A integração no tempo e no espaço, tanto na criança como no adulto sadios, é necessária para a continuidade do ser. Em nosso trabalho, afirma Winnicott, nós temos de tolerar a tensão oriunda dos casos que atendemos, sejam os resultados imediatos ou não, apesar de aprendermos a desconfiar de resultados imediatos. No entanto, em nosso trabalho, aprendemos a desenvolver outros interesses além da técnica e do pagamento pelo nosso trabalho, pois não podemos ignorar o fator tempo no processo de desenvolvimento ou cura demorada do paciente (Winnicott, 1997a).

Em outras palavras, quando acreditamos que o pensamento e 0 segredo assumem uma forma de comunicação silenciosa tácita entre o analista e o seu paciente, podemos compreender finalmente a afirmação de Winnicott (1994b) de que "pensar é pré-dizer".

\section{Referências}

Abram, J. (2000). A linguagem de Winnicott: dicionário das palavras e expressões utilizadas por Donald W. Winnicott (1a. ed.). Rio de Janeiro: Revinter.

Arendt, H. (1995). A vida do espírito: o pensar, o querer, o julgar. Rio de Janeiro: Relume Dumará.

Aulagnier, P. (1990). O direito ao segredo: condição para poder pensar In Um intérprete em busca de sentido - I (pp. 257279). São Paulo: Escuta. (Trabalho original publicado em 1976).

Bion, W. R. (1994). Estudos psicanalíticos revisitados (Second Thoughts). Rio de Janeiro: Imago. (Trabalho original publicado em 1967).

Bion, W. R. (1984). Learning from experience. London: Karnac Books. (Trabalho original publicado em 1962).

Bollas, C. (1992). A sombra do objeto: psicanálise do conhecido não pensado. Rio de Janeiro: Imago. (Trabalho original publicado em 1987).

Bollas, C. (1976). La langage secret de la mère et de l'enfant. Nouvelle Revue de Psychanalyse (Dossier: Du Secret), 14, 241246.

Coblence, F. (2010). La vie d'âme: Psyché est corporelle, n'em sait rien. Revue Française de Psychanalyse, 74(5), 1285-1356. 
Freud, S. (1996a). Breves Escritos: achados, ideias, problemas In Edição Standard Brasileira das Obras Psicológicas Completas de Sigmund Freud. (J. Salomão, trad., Vol. 23, pp. 317-318). Rio de Janeiro: Imago. (Trabalho original publicado em 1941 [1938]).

Freud, S. \& Breur, J. (1996b). Sobre o mecanismo psíquico dos fenômenos histéricos: comunicação preliminar In Edição Standard Brasileira das Obras Psicológicas Completas de Sigmund Freud. (J. Salomão, trad., Vol. 2, pp. 39-56). Rio de Janeiro: Imago. (Trabalho original publicado em 1893).

Green, A. (1977). O outro e a experiência de self In Khan, M. M. R. Psicanálise: teoria, técnica e casos clínicos. Rio de Janeiro: Livraria Francisco Alves Editora. (Trabalho original publicado em 1974).

Grotstein, J. S. (2010). Um facho de intensa escuridão: O legado de Wilfred Bion à Psicanálise. Porto Alegre: Artmed.

Khan, M. M. R. (1989). Hidden selves: between theory and practice in psychoanalysis. London: Maresfield Library.

Khan, M. M. R. (1977a). Silêncio como comunicação In Psicanálise: teoria, técnica e casos clínicos (pp. 205-219). Rio de Janeiro: Francisco Alves. (Trabalho original publicado em 1963).

Khan, M. M. R. (1977b). Regressão e integração no setting analítico. Ensaio clínico sobre os aspectos transferenciais desses fenômenos In Psicanálise: teoria, técnica e casos clínicos (pp. 169-203). Rio de Janeiro: Francisco Alves. (Trabalho original publicado em 1960).

Khan, M. M. R. (1976). Trictrac: d'un secret I'autre. Nouvelle Revue de Psychanalyse (Dossier: Du Secret), 14, 231-239.

Khan, M. M. R. (1974). L'espace du secret. Nouvelle Revue de Psychanalyse - Le dehors et le dedans, 09, 45-56.

Ogden, T. H. (2013). Reading Winnicott In Abram, J. (ed.). Donald Winnicott today (pp. 213-234). London and New York: Routledge/The New Library of Psychoanalysis.

Ogden, T. H. (2010). Esta arte da psicanálise: sonhando sonhos não sonhados e gritos interrompidos. Porto Alegre: Artmed.

Ogden, T. H. (2009). Rediscovering psychoanalysis: thinking and dreaming, learning and forgetting. London and New York: Routledge.

Ogden, T. H. (2001). Conversation at the frontier of dreaming. Northvale, New Jersey: Jason Aronson.

Ogden, T. H. (1999). Reverie and interpretation: sensing something human. London: Karnac.

Ogden, T. H. (1996). Os sujeitos da psicanálise. São Paulo: Casa do psicólogo.

Winnicott, D. W. (2005). Influências de grupo e a criança desajustada: o aspecto escolar In Privação e Delinquência (pp. 
215-226). Porto Alegre: Artmed. (Trabalho original publicado em 1955).

Winnicott, D. W. (1997a). Pensando sobre crianças. Porto Alegre: Artmed.

Winnicott, D. W. (1997b). Notas sobre o fator tempo no tratamento. In Pensando sobre crianças (pp. 202-204). Porto Alegre: Artmed. (Trabalho original publicado em 1961a).

Winnicott, D. W. (1994a). Um caso de psiquiatria infantil que ilustra a reação retardada à perda. In Explorações Psicanalíticas (p. 260282). Porto Alegre: Artmed. (Trabalho original publicado em 1965a).

Winnicott, D. W. (1994b). Uma nova luz sobre o pensar infantil. In Explorações Psicanalíticas (pp. 119-123). Porto Alegre: Artmed. (Trabalho original publicado em 1965b).

Winnicott, D. W. (1994c). O jogo do rabisco [squiggle game]. In Explorações Psicanalíticas (pp. 230-243). Porto Alegre: Artmed. (Trabalho original publicado em 1964-1968).

Winnicott, D. W. (1994d). O pensar e a formação de símbolos In Explorações Psicanalíticas (pp. 167-169). Porto Alegre: Artmed, 1994. (Trabalho original publicado em 1968a).

Winnicott, D. W. (1994e). O uso de um objeto e o relacionamento através de identificações In Explorações Psicanalíticas (pp. 171177). Porto Alegre: Artmed. (Trabalho original publicado em 1968b).

Winnicott, D. W. (1994f). Sobre as bases para o self no corpo In Explorações Psicanalíticas (pp. 203-218). Porto Alegre: Artmed. (Trabalho original publicado em 1970).

Winnicott, D. W. (1983a). Comunicação e falta de comunicação levando ao estudo de certos opostos In $O$ ambiente $e$ os processos de maturação: estudos sobre a teoria do desenvolvimento emocional (pp. 163-174). Porto Alegre: Artmed. (Trabalho original publicado em 1963a).

Winnicott, D. W. (1983b). Distúrbios psiquiátricos e processos de maturação infantil In $O$ ambiente e os processos de maturação: estudos sobre a teoria do desenvolvimento emocional (pp. 207217). Porto Alegre: Artmed. (Trabalho original publicado em 1963b).

Winnicott, D. W. (1983c). Teoria do relacionamento paterno-infantil In $O$ ambiente e os processos de maturação: estudos sobre a teoria do desenvolvimento emocional (pp. 38-54). Porto Alegre: Artmed. (Trabalho original publicado em 1960).

Winnicott, D. W. (1978). Objetos transicionais e fenômenos transicionais In Textos Escolhidos: Da Pediatria à Psicanálise (pp. 389-408). Rio de Janeiro: Francisco Alves. (Trabalho original publicado em 1951). 
Winnicott, D. W. (1975). Objetos transicionais e fenômenos transicionais In $O$ brincar $e$ a realidade (pp. 13-44). Rio de Janeiro: Imago. (Trabalho original publicado em 1953).

\section{Endereço para correspondência}

Sergio Gomes

Universidade Federal do Rio de Janeiro

Instituto de Psicologia - Divisão de Psicologia Aplicada Profa. Isabel Adrados

Av. Pasteur, 250 fundos, Praia Vermelha, CEP 22290-902, Rio de Janeiro - RJ, Brasil

Endereço eletrônico: sergiogsilva@uol.com.br

Recebido em: 25/06/2015

Aceito para: 02/10/2015

\section{Notas}

* Psicanalista, Membro Associado do Círculo Psicanalítico do Rio de Janeiro (CPRJ), Doutor em Psicologia Clínica (PUC-Rio), Supervisor de Estágio da Divisão de Psicologia Aplicada Profa. Isabel Adrados do Instituto de Psicologia da UFRJ. 